\title{
Solubility of amino acids, sugars, and proteins*
}

\author{
Eugénia Almeida Macedo \\ LSRE, Laboratory of Separation and Reaction Engineering, Departamento de \\ Engenharia Química, Faculdade de Engenharia da Universidade do Porto, Rua Dr. \\ Roberto Frias 4200-465 Porto, Portugal
}

\begin{abstract}
The importance of biomolecules is well recognized nowadays, owing to their application in many industrial processes, particularly in the food, pharmaceutical, and cosmetic industries.

Amino acids, carbohydrates, and proteins are the three types of biomolecules considered in this review. Solubilities of several amino acids and sugars have been measured in water and, more recently, in mixed solvents, both with or without salts. Experimental data on partition of proteins in aqueous two-phase systems (ATPSs), with polymers or salts, have also been reported in the literature. The experimental techniques used are briefly discussed. Regarding modeling, the complexity of these solutions is very high. Sugars form strong hydrogen bonds with one another and with water or other solvents like alcohols. Liquid solutions with amino acids or proteins present not only short-range interaction forces, but also long-range forces, owing to the appearance of charged species. The capabilities of different molecular models and group-contribution-based methods are shown.
\end{abstract}

Keywords: amino acids; proteins; sugars; solubility; experimental; modeling.

\section{INTRODUCTION}

Recent advances of the biochemical industry draw much attention to the development of more sophisticated and efficient processes for the separation, concentration, and purification of biomolecules. To design separation processes, accurate thermodynamic models are essential to describe the phase behavior and to calculate the physical chemical properties.

Crystallization is one of the most commonly used techniques for separation and purification of amino acids and sugars, and obviously relies upon the key property of solubility.

The number of available data sets for aqueous mixtures is high, and they are reported in the literature since the late years of the $19^{\text {th }}$ century. Regarding solutions of mixed solvents, the situation is very different. Until the 1990s, the data were very scarce. From then to now, efforts have been made and the solubilities of several amino acids and sugars have been the subject of numerous publications. Therefore, thermodynamic models to represent this property in these systems were only developed and presented during the last decade. Mainly, there are two kinds of approaches: molecular models and group-contribution methods.

Concerning proteins, the great interest is on their partition in aqueous two-phase systems (ATPSs). The purification and concentration of proteins involves, in most cases, the use of an extraction step. However, the selection of a separation agent to extract these biomolecules is limited by the

\footnotetext{
*Paper based on a presentation at the $11^{\text {th }}$ International Symposium on Solubility Phenomena (1 $1^{\text {th }}$ ISSP), Aveiro, Portugal, 25-29 July 2004. Other presentations are published in this issue, pp. 513-665.
} 
potential denaturation that may occur in nonaqueous as well as in aqueous solvents, if the temperature, ionic strength, or $\mathrm{pH}$ conditions are not the "best" ones. Experimental data on the partition of proteins in ATPSs are abundant in the literature, following the first reports in 1956. Modeling of these solutions is very difficult, owing to the high complexity of the biomolecules. There are, however, a few studies on theoretical developments.

\section{AMINO ACIDS}

\section{Experimental data}

The recovery and separation of amino acids frequently involve batch crystallization for which the solubility is the key property that should be available.

The solubility of several amino acids, such as D-alanine, glycine, isoleucine, DL- and L-leucine, DL- and L-aspartic acid, among others, in water in the temperature range from 25 to $100{ }^{\circ} \mathrm{C}$ are known owing to the experimental effort developed in the 1930s by Dalton and Schmidt [1,2] and Dunn et al. [3]. The experimental technique used for the experiments was a very accurate gravimetric method. More recently, data for five cyclic dipeptides were reported at $25^{\circ} \mathrm{C}$ by Kleut and Sijpkes [4]. The authors used an HPLC method for the analysis. In 2002, Matsuo and coworkers [5] published data for $\alpha$-amino acids (glycine, L-alanine, L-valine, L-leucine, and L-isoleucine) in water under high pressure.

Also during the last decade, solubilities of amino acids in binary mixtures of aqueous solutions containing known amounts of other amino acids were reported in the literature, at different temperatures (e.g., L-cystine, L-tyrosine, L-leucine, and glycine, among others, in water [6]).

The effect of both the concentration of a salt and the nature of the cation and the anion in a solution amino acid-water has been studied in the last decade by some research groups [7-10]. The gravimetric method was selected for all studies. Nowadays, the same effects are under study for the aqueous systems of DL-alanine and glycine with $\mathrm{KCl}, \mathrm{Na}_{2} \mathrm{SO}_{4}$, and $\left(\mathrm{NH}_{4}\right)_{2} \mathrm{SO}_{4}$, by Macedo and coworkers [11].

The influence of the $\mathrm{pH}$ on the solubility of amino acids has also been a topic of study. The results indicate that, although in the range of $\mathrm{pH}$ between 2 and 10 there is no significant difference on the solubility [12], outside the isoelectric band, a sharp increase on the solubility is observed [13,14].

Concerning the measurement of amino acids solubility in water-alkanol mixed solvents, the only work published in the last century, taking into account the influence of the temperature is due to Dunn and Ross [15]. In fact, the majority of the data available is at $25^{\circ} \mathrm{C}$ : water-ethanol [16-18], water-methanol [19], and more recently, water-propan-1-ol, water-propan-2-ol [20,21], and water-butan-1-ol [22] systems. With the aim to extend the database already available, new measurements were carried out, by Macedo and coworkers, for glycine and DL-alanine in the aqueous systems of ethanol, propan-1-ol, and propan-2-ol, in the temperature range between 25 and $60{ }^{\circ} \mathrm{C}$, using the analytical gravimetric method [23].

\section{Modeling}

Although data on solubilities of amino acids in water have been available since the 1930s, it was only during the last decade that thermodynamic models were presented for quantitative prediction on this property. There are two main groups of models: (i) those which consider that the amino acid dissociation gives rise to charged species in solution, and take account of long-range forces using a Debye-Hückel term (UNIQUAC model by Peres and Macedo [24], UNIFAC group-contribution method by Pinho et al. [25]); (ii) those which do not consider the long-range interactions, as the amino acid in pure water is mainly in zwitterionic form \{nonrandom two-liquid (NRTL) equation by Chen et al. [26], UNIFAC method by Kuramochi [27], modified Wilson equation by Xu et al. [28]\}. The results obtained are all very satisfactory, being the modified Wilson equation [28] and the UNIQUAC method 
[24] those giving the better predictions. Another approach under development is based on the perturbation theory [29]. The successful results encourage its extension to mixed solvent systems.

For mixed solvent systems, the works by Orella and Kirwan [21] and Gude et al. [22,30] are worth a mention. Orella and Kirwan used an excess solubility approach with the Wilson equation. The solubility data for each amino acid in different alcohol systems were correlated simultaneously to obtain the Wilson parameters between the amino acid and each solvent, obtaining an average relative deviation of about $15.3 \%$ for their measured data with propan-1-ol and propan-2-ol. However, in order to reduce the number of parameters to be estimated, a constraint was established based on the fact that the ratio of the activity coefficients of amino acids in pure solvents should be inversely proportional to the ratio of pure solvent solubilities. Unfortunately, this constraint originates impossible values for the Wilson parameters, since in some cases, like for propan-1-ol-water or propan-2-ol-water mixed solvent systems with L-alanine, the parameters are negative.

Gude et al. [22,30] presented a simpler model, also based on the excess solubility approach, which is a combination of a combinatorial term based on the Flory-Huggins (FH) theory with a Margules residual expression. This methodology is very attractive because simultaneous representation of solid-liquid and liquid-liquid equilibria with only one ternary Margules interaction parameter is achieved. The results are very similar to those obtained by Orella and Kirwan [21], but the number of parameters is much lower. In fact, the authors use a unique specific interaction parameter for each amino acid in different aqueous alkanol solutions, which allows a straightforward method to predict amino acid solubilities and partition coefficients in alkanol-water solvent systems. However, the application of this model to the description of the solubility of amino acids in water-methanol solvents (usually the easiest to correlate) leads to an average relative deviation of $27.7 \%$.

In view of the difficulties encountered with the previous methods, Ferreira et al. [23] used the excess solubility approach with conventional thermodynamic models like the Margules, Wilson, and nonrandom two-liquid (NRTL) equations. The NRTL model gave the best fit of the data, with average relative deviations around $8.4 \%$ for correlation and $15.0 \%$ for predictions. An important feature of a model is the predictive capability. Figure 1 shows a comparison of the performance of the model presented by Ferreira et al. [23] in the prediction of solubility data for glycine in water-ethanol mixtures at different temperatures published by Dunn and Ross [15].

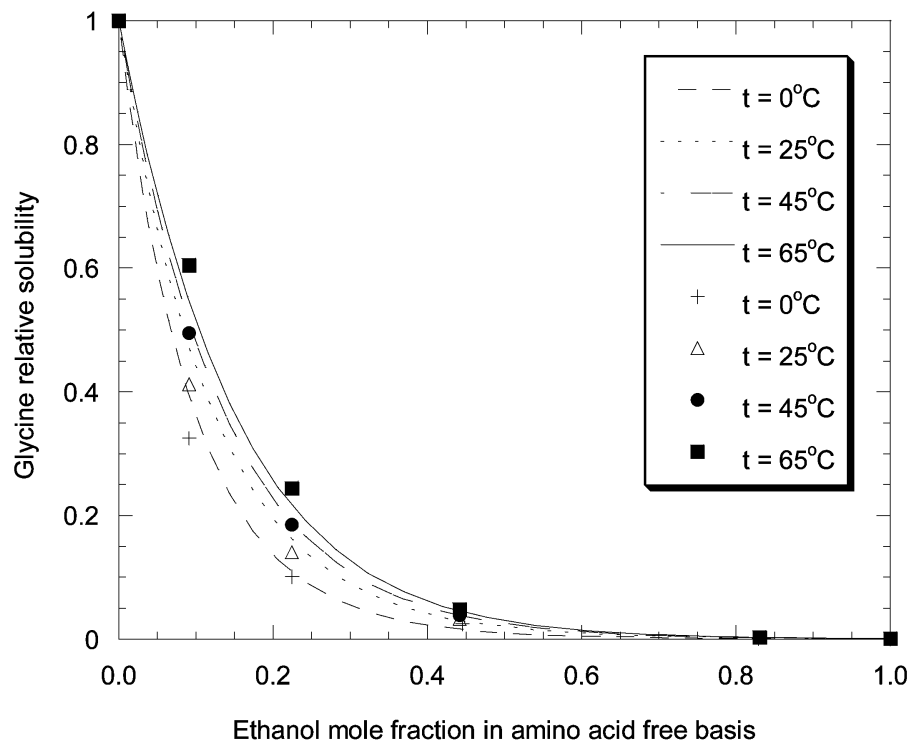

Fig. 1 NRTL predictions of the relative solubility of glycine and water-ethanol mixtures [15]. 


\section{SUGARS}

\section{Experimental data}

\section{Sugar(s)-water systems}

Solubility data of several sugars and their derivatives in water have been measured and published since the late years of the $19^{\text {th }}$ century. From then until now, there was an increasing interest in these mixtures, especially with the development of food and pharmaceutical industries, and, therefore, more solubility data have been presented. It was possible to collect most of this information. Table 1 gives an overview of available solubility data for the most widely used sugars. For each sugar-water system, there is an indication of the temperature range for which the solubilities were measured, together with the bibliographic references containing the information.

Table 1 Solubilities of sugars in water.

\begin{tabular}{lcl}
\hline Systems & Temperature range & \multicolumn{1}{c}{ References } \\
\hline D-Glucose-water & $-12.06-90.8^{\circ} \mathrm{C}$ & {$[31-35]$} \\
D-Fructose-water & $-3.85-70{ }^{\circ} \mathrm{C}$ & {$[35-38]$} \\
Sucrose-water & $-3-100^{\circ} \mathrm{C}$ & {$[31,33,34,39]$} \\
Maltose-water & $0-100^{\circ} \mathrm{C}$ & {$[31,33,34,40,41]$} \\
Lactose-water & $-3-100{ }^{\circ} \mathrm{C}$ & {$[31,33,34,40,42-45]$} \\
D-Galactose-water & $25-85^{\circ} \mathrm{C}$ & {$[31,41]$} \\
Raffinose-water & $0-100^{\circ} \mathrm{C}$ & {$[31,41,46]$} \\
D-Xylose-water & $25-85^{\circ} \mathrm{C}$ & {$[41,47]$} \\
Mannose-water & $25-35^{\circ} \mathrm{C}$ & {$[47]$} \\
Cellobiose-water & $25-85^{\circ} \mathrm{C}$ & {$[41,48]$} \\
Trehalose-water & $25-85^{\circ} \mathrm{C}$ & {$[41]$} \\
\hline
\end{tabular}

The data presented in Table 1 were measured using mainly two different techniques. One consists of weighing the samples taken from the liquid phase until evaporation of the water is complete. Usually, the samples are filtered before drying. The other method depends on the observation of the disappearance of the last crystal. Although this last technique is faster, it has the disadvantage of achieving less accurate results [38]. Usually, the accuracy obtained using the evaporation plus weighing method is better than $1 \%[40,47]$.

The importance of crystallization of sugars for the production of refined sucrose, honey, and sweets increased the interest in mixed sugars-water systems, namely, D-glucose-sucrose-water and D-fructose-sucrose-water [35]. Other experimental studies were carried out for the ternary system D-xylose-D-mannose-water [47].

The effect of salts $\left(\mathrm{NaCl}, \mathrm{KCl}, \mathrm{K}_{2} \mathrm{SO}_{4}\right.$, etc.) has been investigated for a long time [33,40], for a variety of sugars and their derivatives, and is still nowadays a subject of interest [45], since it is not yet possible to foresee the change of the solubility with the amount or type of electrolyte added.

\section{Nonaqueous systems and mixed solvents}

The solubilities of sugars in nonaqueous solvents have also been presented in the literature for a long time. Although there are many data sets available, it is important to remark that they are not all in agreement with each other, and for some systems the range of temperatures covered is narrow.

As far as mixed solvents are concerned, data were very scarce until the last decade, in despite of their importance for modeling purposes and for separation process design and scale-up. During the early 1990s, a systematic experimental program was implemented, with the purpose of covering this big lack of data. Data are now available for D-glucose in water-methanol, water-ethanol, and methanol-ethanol at 35, 40, and $60{ }^{\circ} \mathrm{C}$ [49-51], D-fructose in water-methanol, water-ethanol and methanol-ethanol at 25,40 , and $60^{\circ} \mathrm{C}$ [52,53], D-mannose and D-xylose in water-ethanol at $25^{\circ} \mathrm{C}$ [54], 
sucrose in water-methanol, water-ethanol, and methanol-ethanol at 25,40 , and $60{ }^{\circ} \mathrm{C}$ [55] and lactose in water-ethanol at 25,40 , and $60{ }^{\circ} \mathrm{C}[56]$.

An IUPAC project is currently in progress to compile and evaluate comprehensive solubility data for sugars [57].

\section{Modeling}

Several approaches have been commonly used to estimate properties of sugar solutions. These can be divided into two classes: "statistical" and thermodynamic models. The first ones, called statistical by Leschke [58], were adopted by Kononenko and Herstein [59] and by Vasátko and Smelík [38] to represent the sugar solubility (D-fructose, sucrose) with the temperature using a polynomial.

In more recent years, authors became more acquainted with the potentialities of applying thermodynamic models to the study of different properties of sugar solutions. Some researchers used a molecular approach, like the modified UNIQUAC models presented by Catté et al. [60] and by Peres and Macedo [61]. The model proposed by Peres and Macedo [61] contrasts with the other one because fewer parameters are used for each sugar-water pair, since a simpler dependence with temperature is used. The great advantage, however, lies in the fact that Peres and Macedo [61] use the symmetric convention for all components, allowing a straightforward extension of the method for the correlation and prediction of solid-liquid equilibria in mixed solvent systems, which is not possible for the model of Catté et al. [60], as these authors chose the unsymmetric convention for the activity coefficient calculations.

However, the majority of the models, follow a group-contribution methodology, mainly because of their predictive nature. Some different modified UNIFAC-based methods are available in the literature. Abed et al. [35] and Gabas and Laguérie [62] used a modified version of the UNIFAC method to predict the solid-liquid equilibrium data in ternary systems of two sugars-water. In 1997, Peres and Macedo [63] proposed a new modification of the UNIFAC (P\&M) model for sugar solutions. In both models, new groups were defined to represent the rings of the sugars molecules, owing to proximity effects. Comparison of predictions for solubilities of sugars in mixed solvents showed that the P\&M model gives better results than the Gabas and Laguérie [62] model. This is illustrated in Fig. 2. Another UNIFAC method was published by Spiliotis et al. [64] specially to predict partition coefficients of sugars. The liquid-liquid equilibria UNIFAC table of parameters was used.

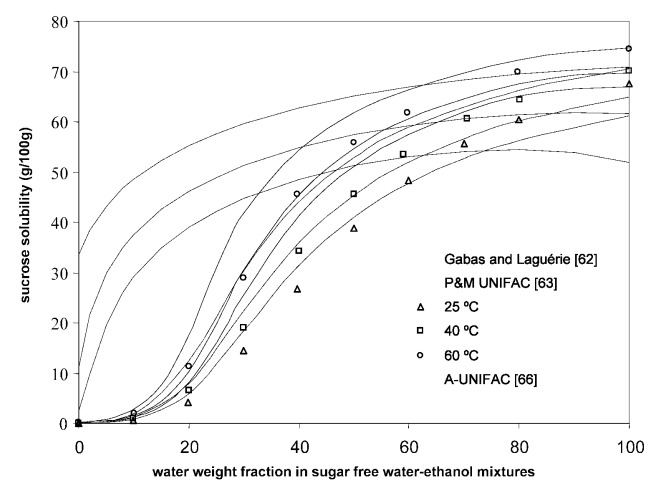

Fig. 2 Solubility of sucrose in water-ethanol at 25,40 , and $60{ }^{\circ} \mathrm{C}$ : comparison of the experimental data with predictions from different UNIFAC methods. 
Catté et al. [65] established a new physical-chemical UNIFAC-based model to describe the thermodynamic properties of sugar-water mixtures (D-glucose, D-fructose, D-mannose, D-galactose, sucrose, maltose, and lactose). The chemical equilibrium considers solvation and conformation phenomena, which is not the case of the previously mentioned models. The main drawbacks of this method are the fact that it uses the unsymmetric convention and it is only applicable to aqueous mixtures and not to mixed solvents, because equilibria information about conformers in other solvents than water is not available.

Sugars form strong hydrogen bonds with one another and with water or other solvents like alcohols. Accordingly, more recently, Ferreira et al. [66] applied a UNIFAC-based method with a specific term to take account of association effects (A-UNIFAC). Figure 2 presents experimental data for sucrose in water-ethanol and predictions from the UNIFAC methods proposed by Gabas and Laguérie [62], Peres and Macedo [63], and Ferreira et al. [66]. It is clear that the first model is totally inadequate to represent the data, that the P\&M model gives a fair prediction while the A-UNIFAC describes the data accurately $(\mathrm{AAD}=8.81 \%)$. Figure 3 shows the experimental data for $\mathrm{D}$-glucose in methanol-ethanol with predictions from P\&M $(\mathrm{AAD}=28.1 \%)$ and A-UNIFAC $(\mathrm{AAD}=15.8 \%)$ models. This is the trend generally observed for solubilities of sugars in mixed solvents.

Molecular mechanics methods were used by Jónsdóttir [41] to predict, among other properties, solubilities of carbohydrates, but this methodology was restricted to aqueous solutions. The predictions were very satisfactory, showing that this is a promising area to be developed in the future.

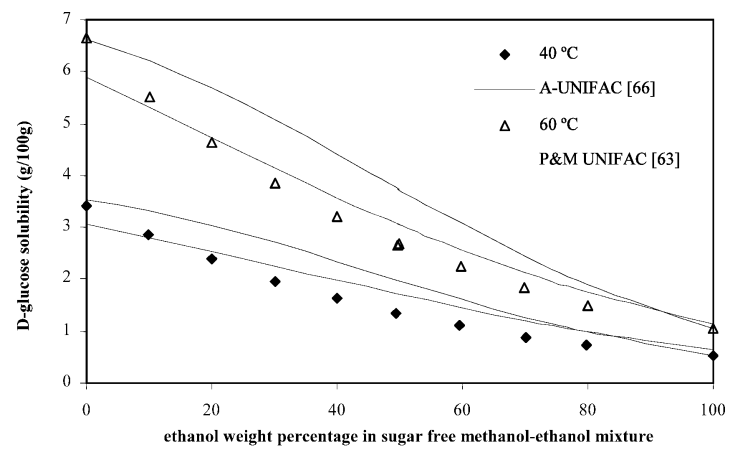

Fig. 3 Solubility of D-glucose in methanol-ethanol at 40 and $60{ }^{\circ} \mathrm{C}$ : comparison of the experimental data with predictions from P\&M UNIFAC and A-UNIFAC.

\section{PROTEINS}

\section{Experimental data}

The first publication on experimental measurements about protein in ATPS partition is due to Albertsson [67]. The system studied was the protein catalase in aqueous dextran (Dex) with methylcellulose. After the 1970s, other authors (e.g., Johansson [68]) presented additional data on protein partition in poly(ethylene glycol) (PEG)-Dex aqueous solutions, but it was only during the last decade that an increasing interest in these systems was shown, and most of the publications on the topic were made available.

The technological domains where proteins have potential use are vast, and include medicine, food industry, biotechnology, chemical industry, environmental technology, textile industry, etc. Thus, we may find every kind of protein studied by the ATPS technology. Nevertheless, there are some proteins that have been the object of more intense research than others. Among these are the bovine serum al- 
bumin (BSA), in great majority, followed by others, like lysozyme, $\alpha$ - and $\beta$-galactosidade, $\alpha$ - and $\beta$-amylase, casein, cutinase, $\gamma$-globulyn, and endopolygalacturonase. The maintenance of the proteins' enzymatic activity is one of the primary concerns when processing such biomolecules. Thus, the temperature ranges in which the partition experiments are carried out usually lie between 283 and $313 \mathrm{~K}$, since beyond those limits the proteins may irreversibly denaturate.

The most widely used ATPSs are those composed of PEG and Dex [69]. Other polysaccharides (such as REPPAL, a modified starch and cellulose derivative) have also been proposed as phase-forming polymers. Much attention is given nowadays to systems composed of thermoseparating polymers, where PEG is replaced by a polymer that has a low cloud-point temperature, as is the case of EOPO (e.g, [70,71]).

Among the systems of one polymer and one salt, the PEG-potassium phosphate is the most popular polymer-salt system $[69,72]$. It is also possible to find experimental data for PEG with magnesium sulfate and ammonium sulfate.

After addition of a protein to an ATPS, the system will attain equilibrium and the solute will partition between both phases. The time needed to reach equilibrium depends very much on the system: PEG-salts take a few minutes, while PEG-polymers may take more than half an hour (obviously, this will depend on the method used for phase separation-gravity sedimentation or centrifugation). The solute's "preference" for a given phase (top or bottom) is usually quantified by the partition coefficient, $K$, commonly defined as the protein concentration on the top phase divided by its concentration on the bottom phase. The experimental technique usually used to measure the protein concentration is $\mathrm{UV} / \mathrm{vis}$ spectroscopy at $280 \mathrm{~nm}$.

\section{Modeling}

It is common practice to express the partition of proteins in ATPSs in terms of the protein net surface charge, the electrical potential difference between both phases and other properties (such as temperature), and the partition coefficient of the same protein in the absence of either a net charge or an electrical potential difference [69].

According to this methodology, it is necessary to obtain the electrical potential difference between both phases and a way to calculate the net charge of the protein. The electrical potential difference between the aqueous phases is attributed to the unevenly distribution of the ionic species and seems to play an important role in the partition of proteins in ATPSs [73,74]. Despite the predominant influence of the electrical contribution on the partition of charged proteins, some doubt remains about the experimental assessment as well as about the theoretical explanation of the electrical potential difference between phases (see, e.g., [73]). The application of the quasi-electrostatic-potential theory developed by Newman [75] is one of the most widely used approaches to calculate it $[73,76]$.

The partition coefficient of the same protein in the absence of any net charge or electrical potential difference is calculated using a model for the excess Gibbs energy. The models proposed to represent this property can be divided into two main groups: models based on the lattice theory and the osmotic virial expansion equations.

The first attempts to correlate protein partition coefficients were reported by Brooks et al. [77] using the FH lattice theory. Diamond and Hsu [78] used a linearized form of the FH theory to obtain a semiempirical expression for protein partition in polymer-polymer ATPSs with or without salts. The FH model was also used by Hino and Prausnitz [79]. A modified lattice theory was coupled to a Pitzer equation to describe long-range interactions by Peng et al. [80], for protein partitioning in polymer-salt systems.

The osmotic virial expansion, first introduced by Edmond and Ogston [81], provided a simple theoretical framework for ATPSs. This methodology was adopted by King et al. [82] and Haynes et al. [76] to predict some protein partitioning in polymer-polymer mixtures in the presence or absence of salts. Wu et al. [83] and Gaube et al. [84], among other authors, performed similar studies. 
Very recently, Madeira et al. [85] applied a modified Wilson equation, previously developed to predict vapor-liquid [86] and liquid-liquid equilibria of ATPSs containing polymers and salts [87], to represent the partitioning of BSA, lysozyme, glucosidase, and catalase in the $\mathrm{Na}_{2} \mathrm{SO}_{4}-\mathrm{PEG} 6000$-water and $\mathrm{K}_{2} \mathrm{HPO}_{4}-\mathrm{PEG6000}$-water ATPSs. Although some assumptions were introduced in the predictive methodology, the results were, in some cases, very satisfactory. This can be observed from Fig. 4. As the experimental data available in the literature are scarce, the major discrepancies found were attributed to the lack of experimental data available.

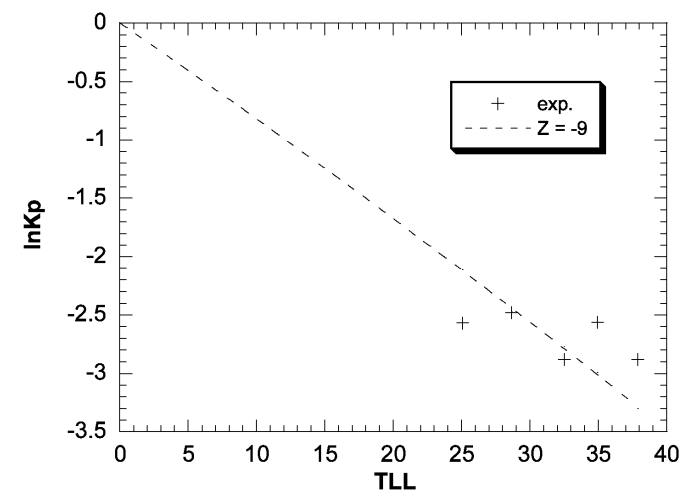

Fig. 4 Calculated and experimental (+) partition coefficient of BSA in the PEG6000- $\mathrm{Na}_{2} \mathrm{SO}_{4}$ ATPS at 298.15 K.

\section{CONCLUSIONS}

This work focused on solubilities of amino acids, sugars. and proteins. An overview of both experimental data and thermodynamic models available was given. Experimental data for aqueous systems have been available for a long time, while mixed solvent systems were only studied during the last decade. It is necessary to extend the measurements over larger concentration, temperature, and pressure ranges. At a theoretical level, efforts were mainly concentrated on the establishment of molecular and group-contribution models. These can represent very accurately aqueous solution solubilities and are, in general, fair for mixed solvent systems. In view of improving the predictive capabilities, it is fundamental to develop new models taking into consideration the different specific interactions in solution.

\section{ACKNOWLEDGMENTS}

The author is very grateful to Dr. Simão P. Pinho for helpful and valuable suggestions and to Dr. Olga Ferreira, Ms. Luísa A. Ferreira, and Mr. Pedro Madeira for their collaboration in the preparation of this work.

\section{REFERENCES}

1. J. B. Dalton and C. L. A. Schmidt. J. Biol. Chem. 103, 549 (1933).

2. J. B. Dalton and C. L. A. Schmidt. J. Biol. Chem. 109, 241 (1935).

3. M. S. Dunn, F. J. Ross, L. S. Read. J. Biol. Chem. 103, 579 (1933).

4. G. J. Kleut and A. H. Sijpkes. J. Chem. Thermodyn. 26, 1115 (1994).

5. H. Matsuo, Y. Suzuki, S. Sawamura. Fluid Phase Equilib. 200, 227 (2002).

6. R. Carta. J. Chem. Eng. Data 44 (3), 563 (1999).

7. M. K. Khoshkbarchi and J. H. Vera. Ind. Eng. Chem. Res. 36 (6), 2445 (1997).

8. A. Soto, A. Arce, M. K. Khoshkbarchi, J. H. Vera. Biophys. Chem. 73, 77 (1998).

9. A. A. Pradhan and J. H. Vera. J. Chem. Eng. Data 45 (1), 140 (2000). 
10. P. Ramasami. J. Chem. Eng. Data 47, 1164 (2002).

11. L. A. Ferreira, E. A. Macedo, S. P. Pinho. Proc. $11^{\text {th }}$ International Symposium on Solubility Phenomena, IUPAC, p. 43, Aveiro, Portugal (2004).

12. A. A. Pradhan and J. H. Vera. Fluid Phase Equilib. 152, 121 (1998).

13. T. E. Needham, A. N. Paruta, R. J. Gerraughty. J. Pharm. Sci. 60 (4), 565 (1971).

14. R. Carta. J. Chem. Thermodyn. 30, 379 (1998).

15. M. S. Dunn and F. J. Ross. J. Biol. Chem. 125, 309 (1938).

16. E. J. Cohn, T. L. McMeekin, J. T. Edsall, J. H. Weare. J. Am. Chem. Soc. 56, 2270 (1934).

17. T. L. McMeekin, E. J. Cohn, J. H. Weare. J. Am. Chem. Soc. 57, 626 (1935).

18. Y. Nozaki and C. Tanford. J. Biol. Chem. 246, 2211 (1971).

19. K. Gekko. J. Biochem. 90, 1633 (1981).

20. C. J. Orella and D. J. Kirwan. Biotechnol. Prog. 5, 89 (1989).

21. C. J. Orella and D. J. Kirwan. Ind. Eng. Chem. Res. 30, 1040 (1991).

22. M. T. Gude, H. H. J. Meuwissen, L. A. M. Wielen, K. Ch. A. M. Luyben. Ind. Eng. Chem. Res. 35, 4700 (1996).

23. L. A. Ferreira, S. P. Pinho, E. A. Macedo. Chem. Eng. Sci. 59, 3117 (2004).

24. A. M. Peres and E. A. Macedo. Chem. Eng. Sci. 49, 3803 (1994).

25. S. P. Pinho, C. M. Silva, E. A. Macedo. Ind. Eng. Chem. Res. 33, 1341 (1994).

26. C. C. Chen, Y. Zhu, L. B. Evans. Biotechnol. Prog. 5, 111 (1989).

27. H. Kuramochi, H. Noritomi, D. Hoshino, K. Nagahama. Biotechnol. Prog. 12, 371 (1996).

28. X. Xu, S. P. Pinho, E. A. Macedo. Ind. Eng. Chem. Res. 43, 3200 (2004).

29. J. Liu, J. Lu, Y. Li. Fluid Phase Equilib. 142, 67 (1998).

30. M. T. Gude, L. A. M. Wielen, K. Ch. A. M. Luyben. Fluid Phase Equilib. 116, 110 (1996).

31. W. M. Dehn. J. Am. Chem. Soc. 39, 1399 (1917).

32. F. E. Young. J. Phys. Chem. 61, 616 (1957).

33. H. Stephen and T. Stephen. Solubilities of Inorganic and Organic Compounds: Binary Systems, Vol. 1, Parts I and II, Pergamon Press, Oxford (1963).

34. J. W. Mullin. Crystallisation, $2^{\text {nd }}$ ed., Butterworths, London (1972).

35. Y. Abed, N. Gabas, M. L. Delia, T. Bounahmidi. Fluid Phase Equilib. 73, 175 (1992).

36. R. F. Jackson, C. G. Silsbee, M. J. Profitt. Sci. Papers Bur. Standards 20, 588 (1926).

37. F. E. Young, F. T. Jones, H. J. Lewis. J. Phys. Chem. 56, 1093 (1952).

38. J. Vasátko and A. Smelík. Chem. Zvesti 21, 736 (1967).

39. F. E. Young and F. T. Jones. J. Phys. Chem. 53, 1334 (1949).

40. C. S. Hudson. J. Am. Chem. Soc. 30, 1767 (1908).

41. S. O. Jónsdóttir, S. A. Cooke, E. A. Macedo. Carbohydr. Res. 337, 1563 (2002).

42. M. J. Gillis. Rec. Trav. Chim. 39, 88 (1920).

43. M. J. Gillis. Rec. Trav. Chim. 39, 677 (1920).

44. P. N. Peter. J. Phys. Chem. 32, 1856 (1928).

45. A. Bhargava and P. Jelen. J. Food Sci. 61, 180 (1996).

46. E. H. Hungerford and A. R. Nees. Ind. Eng. Chem. 26, 462 (1934).

47. N. Gabas and C. Laguérie. Bull. Soc. Chim. Fr. 127, 391 (1990).

48. J. B. Taylor. Trans. Faraday Soc. 53, 1198 (1957).

49. G. L. Bockstanz, M. Buffa, C. T. Lira. J. Chem. Eng. Data 34, 426 (1989).

50. A. M. Peres and E. A. Macedo. Entropie 202/203, 71 (1997).

51. A. M. Peres and E. A. Macedo. Ind. Eng. Chem. Res. 36, 2816 (1997).

52. A. E. Flood, J. Addai-Mensah, M. R. Johns, E. T. White. J. Chem. Eng. Data 41, 418 (1996).

53. E. A. Macedo and A. M. Peres. Ind. Eng. Chem. Res. 40, 4633 (2001).

54. N. Gabas, T. Carillon, N. Hiquily. J. Chem. Eng. Data 33, 128 (1988).

55. A. M. Peres and E. A. Macedo. Carbohydr. Res. 303, 135 (1997).

56. J. J. B. Machado, J. A. P. Coutinho, E. A. Macedo. Fluid Phase Equilib. 173, 121-134 (2000). 
57. IUPAC Subcommittee on Solubility and Equilibrium Data. Unpublished results (2004).

58. R. J. Leschke. Biotechnol. Progr. 3, 205 (1987).

59. O. K. Kononenko and K. M. Herstein. Ind. Chem. Eng. Chem. 1, 87 (1953).

60. M. Catté, C. G. Dussap, C. Achard, J. B. Gros. Fluid Phase Equilib. 96, 33 (1994).

61. A. M. Peres and E. A. Macedo. Fluid Phase Equilib. 123, 71 (1996).

62. N. Gabas and C. Laguérie. J. Cryst. Growth 128, 1245 (1993).

63. A. M. Peres and E. A. Macedo. Fluid Phase Equilib. 139, 47 (1997).

64. N. Spiliotis and D. Tassios. Fluid Phase Equilib. 173, 39 (2000).

65. M. Catté, C. G. Dussap, J. B. Gros. Fluid Phase Equilib. 105, 1 (1995).

66. O. Ferreira, E. A. Brignole, E. A. Macedo. Ind. Eng. Chem. Res. 42, 6212 (2003).

67. P.-Å. Albertsson. Nature 177, 771 (1956).

68. G. Johansson. Biochim. Biophy. Acta 451, 517 (1976).

69. P.- $\AA$. Albertsson. Partition of Cell Particles and Macromolecules, $3^{\text {rd }}$ ed. Wiley-Interscience, New York (1986).

70. J. Persson, H.-O. Johansson, F. Tjerneld. J. Chromatogr., A 864, 31 (1999).

71. M. Pereira, Y.-T. Wu, A. Venâncio. J. Teixeira. Biochem. Eng. J. 3691, 1 (2003).

72. J. Huddleston, A. Veide, K. Köhler, J. Flanagan, S. O. Enfors, A. Lyddiatt. Tibtech. 9, 381 (1991).

73. C. A. Haynes, J. Carson, H. W. Blanch, J. M. Prausnitz. AIChE J. 37, 1401 (1991).

74. C. A. Haynes, F. J. Benitez, H. W. Blanch, J. M. Prausnitz. AIChE J. 39, 1539 (1993).

75. J. S. Newman. Electrochemical Systems, Prentice-Hall, Englewood Cliffs, NJ (1973).

76. C. A. Haynes, H. W. Blanch, J. M. Prausnitz. Fluid Phase Equilib. 53, 463 (1989).

77. D. E. Brooks, K. A. Sharp, D. Fisher. In Partitioning in Aqueous Two-phase Systems. Theory, Methods, Uses, and Applications to Biotechnology, H. Walter, D. E. Brooks, D. Fisher (Eds.), Academic Press, London (1985).

78. A. D. Diamond and J. T. Hsu. Biotechnol. Bioeng. 34, 1000 (1989).

79. T. Hino and J. M. Prausnitz. J. Appl. Polym. Sci. 68, 2007 (1998).

80. Q. Peng, Z. Li, Y. Li. Fluid Phase Equilib. 95, 341 (1994).

81. E. Edmond and A. Ogston. Biochem. J. 109, 569 (1968).

82. R. S. King, H. W. Blanch, J. M. Prausnitz. AIChE J. 34, 1585 (1988).

83. Y.-T. Wu, Z.-Q. Zhu, D.-Q. Lin, L. H. Mei. Fluid Phase Equilib. 121, 125 (1996).

84. J. Gaube, A. E. Pfenning, M. J. Stumpf. Chem. Eng. Data 38, 163 (1993).

85. P. P. Madeira, X. Xu, J. A. Teixeira, E. A. Macedo. Proc. $11^{\text {th }}$ International Symposium on Solubility Phenomena, IUPAC, p. 111, Aveiro, Portugal (2004).

86. X. Xu, P. P. Madeira, J. A. Teixeira, E. A. Macedo. Fluid Phase Equilib. 213, 53 (2003).

87. X. Xu, P. P. Madeira, E. A. Macedo. Chem. Eng. Sci. 59, 1153 (2004). 